\title{
The increased effect of a visual training procedure after sensory restriction
}

DAVID G. MARTIN, UNIVERSITY OF IOWA: PAUL ROUSH, ILLINOIS COLLEGE OF OPTOMETRY JAMES NICHOLSON, UNIVERSITY OF IOWA

Eighty-four undergraduates, previously identified as having an esophoric condition, were divided into two experimental groups: (1) sensory restriction followed by visual training, (2) pattemed stimulation followed by visual training, and four control groups, two receiving pseudo-training and two no training. The effect of the training procedure was enhanced by a preceding period of sensory restriction.

Recent interest in the effects of sensory restriction on perceptual functioning has resulted in two conflicting general findings. One set of findings demonstrated that periods of non-patterned deprivation effected a general deficit in cognitive and perceptual functioning (Heron, Bexton, \& Hebb, 1953; Bexton, Heron, \& Scott, 1954; Heron, 1957). In contrast, many workers (Friel \& Derogatis, 1965; Doane, Mahatoo, Heron, \& Scott, 1959; Rosenbaum, Dobie, \& Cohen, 1959; Zubek, Flye, \& Aftanas, 1964; Shultz, 1965) have reported that periods of deprivation resulted in the enhancement of cognitive and perceptual functioning. Friel and Derogatis have attempted to resolve the discrepancies between these general findings. They stated that the studies reporting impaired functioning involved prolonged periods of deprivation which may have gone beyond a point of maximum enhancement of functioning.

The present study was designed to examine the effect of stimulus restriction on neuromuscular functioning. It was hypothesized that a neuromuscular visual training procedure outlined by Manas $(1965,1967)$ would have a more pronounced effect after a brief $(45 \mathrm{~min})$ period of restricted stimulation than after a similar period of patterned auditory and visual stimulation. The training procedure chosen was designed to correct esophoria, a neurological deficit defined by Duke-Elder (1949) as a tendency of the eyes to deviate inward stemming from neurological imbalance. This particular visual defect was chosen because of its high frequency among college students, the population from which the sample was drawn. It was further hypothesized that all Ss receiving visual training would show a more pronounced improvement in their esophoric condition than would Ss receiving a control condition of either pseudo-training or no training at all.

Subjects

Eighty-four undergraduate students (53 female, 31 male) in an elementary psychology course at the University of Iowa served as Ss. Prior to the experiment, each $\mathrm{S}$ had been identified as having an esophoric condition by a screening procedure utilizing the Keystone Stereoscope and Keystone card number DB9B. Each $\mathrm{S}$ was assigned to one of six experimental or control groups depending on the time he signed up to participate in the experiment. Each group was scheduled so that an equal number of Ss was run at any one time of day. The two experimental groups were: (1) sensory restriction, followed by visual training, and (2) a period of patterned stimulation followed by visual training. The four control groups were: (1) restriction with pseudo-training, (2) stimulation with pseudo-training, (3) restriction with no training, and (4) stimulation with no training. Analysis of variance indicated that none of the six groups differed in degree of esophoria prior to the experimental procedure $(F=1.86, \mathrm{df}=1 / 78)$.

\section{Apparatus and Facilities}

The entire experiment was run in an anechoic chamber which measured $7 \mathrm{ft} 8 \mathrm{in}$. by $13 \mathrm{ft} 8 \mathrm{in}$. The visual training procedure was carried out with a TDC stereo projector, Model No. 111, utilizing a $500 \mathrm{~W}$ projection bulb for each lens. A TDC stereo projection screen was placed at a distance of $9 \mathrm{ft} 7 \mathrm{in}$. from the projector. During the visual training procedure, Ss were seated immediately in front of the projector, and the distance from eye to screen was $8 \mathrm{ft}$. Each $S$ was seated in a comfortable, padded straight chair with no arms. The visual training procedure utilized slide number BA24 produced by the Stereo Optical Company. A masking noise was provided for the sensory restriction by a tape recording of white noise which was heard through earphones. The sound pressure level at the earphones was $92 \mathrm{~dB}( \pm 2 \mathrm{~dB})$.

\section{Procedures}

The Ss were given a brief explanation of the procedures to follow and were then led into the anechoic chamber. Immediately preceding the experimental procedure, each $\mathrm{S}$ was tested with a phorometer, and his degree of esophoria was recorded. Immediately following the experimental procedure, each $S$ was again tested with a phorometer, and a score of change in phoric condition was assigned. Improvement was defined as movement in the exophoric direction on the phorometer test.

The sensory restriction condition consisted of white noise and sitting in total darkness for $45 \mathrm{~min}$. The Ss were instructed to sit with their hands in their laps and to make no sound or movement. A monitoring microphone indicated that all Ss followed the directions and produced neither sound nor audible movement.

The stimulation condition consisted of $45 \mathrm{~min}$ of listening to humorous recordings and ranking them according to their humorousness. Visual stimulation was provided by illuminating the anechoic chamber and having two or three other Ss in the room.

To begin the visual training procedure, Ss were instructed to put on polarized glasses immediately after the experimental condition and to concentrate 
Table 1

Mean Improvement: Diopters Change in the Exophoric Direction

\begin{tabular}{cccc}
\hline & $\begin{array}{c}\text { Visual } \\
\text { Training }\end{array}$ & $\begin{array}{c}\text { Pseudo- } \\
\text { Training }\end{array}$ & $\begin{array}{c}\text { No } \\
\text { Training }\end{array}$ \\
\hline Restriction & $3.56(\mathrm{~N}=15)$ & $.60(\mathrm{~N}=15)$ & $.07(\mathrm{~N}=15)$ \\
& $\mathrm{SD}=2.85$ & $\mathrm{SD}=2.32$ & $\mathrm{SD}=2.17$ \\
Stimulation & $.85(\mathrm{~N}=13)$ & $.19(\mathrm{~N}=13)$ & $1.58(\mathrm{~N}=13)$ \\
& $\mathrm{SD}=1.37$ & $\mathrm{SD}=1.39$ & $\mathrm{SD}=1.57$
\end{tabular}

on "E-4" in the projected image on the screen. ("E-4" was a "4" in a small circle at approximately the center of the projected image.) The Ss were then instructed to concentrate on this circle and to try to maintain it as one image. The $E$ then separated the projected images horizontally on the screen with a steady motion so that at the end of 30 sec the right-hand image of "E-4" corresponded to the position of "E-6" on the left-hand image. During this separation procedure, each $S$ was told to close his eyes when he could no longer maintain " $\mathrm{E}-4$ " as a single image. This procedure was repeated 20 times for each of the visual training Ss. The pseudotraining appeared to be a similar procedure but lacked the essential element of separating the eyes in a horizontal direction.

Results

Table 1 presents the mean improvement scores for each group. The results are reported in diopters of change in the exophoric direction. Analysis of variance demonstrated the presence of a significant training method effect $(F=6.24, \mathrm{df}=2 / 78, \mathrm{p}<.005)$, with Ss receiving visual training improving more than control Ss. Stimulation level was not a significant source of variance $(F=1.34$, df $=1 / 78)$. A significant interaction effect $(F=6.89, \mathrm{df}=2 / 78, \mathrm{p}<.005)$ demonstrated greater improvement in the group receiving sensory restriction plus visual training than in any other group. Both hypotheses of the study were supported statistically. However, the positive results for the second hypothesis, that visual training Ss showed more improvement than control $\mathrm{Ss}$, is not clearly interpretable. The presence of the strong interaction effect favoring the restriction plus training group accounts for the main effect favoring all visual training Ss. Further, $t$ test comparisons between the stimulation plus training group and the four control groups revealed no differences large enough to justify rejection of the null hypothesis.

\section{Discussion}

The findings of the present study are consistent with the position that stimulus restriction enhances neuromuscular functioning. Explanations of this enhancement effect have included postulating an increasirg "hunger" for stimulation (Friel \& Derogatis, 1965). A perhaps more parsimonious conception of this position is that restricted stimulation leads to a neurologically sensitized organism. Riesen (1961) demonstrated that motor neurons became hypersensi- tive in the absence of external stimulation, suggesting a basis for an increased neurological sensitivity after restriction. The present findings are consistent with this position but do not exclude the possibility that muscular relaxation during the restriction condition contributed to the enhancement of training. Vernon \& Hoffman (1956), for example, theorized that sensory isolation would facilitate the learning process because of the absence of extraneous inhibiting stimuli.

An additional relevant theoretical position is that of Lindsley (1961), who suggested that the reticular formation has an adaptation level that becomes adjusted to specific levels of stimulation. This level is projected on the cortex where it influences perception and learning, and may become upset in variations in sensory input. Thus, the deprived $S$ is more susceptible to training as he becomes increasingly sensitized to stimulation in an attempt to gain his optimal level. Acuity is raised and the training (stimulus variability) assumes reinforcing properties.

Further research in this area should include study of a possible curvilinear relationship between the length of deprivation and the enhancement of functioning, and of the effect of isolation of specific sensory modalities (e.g., the effect of restricting only vision or only hearing on visual functioning).

\section{References}

Bexton, W. H., Heron, W., \& Scott, T. H. Effects of decreased variation in the sensory environment. Canad. J. Psychol., 1954, 8,70 .

Doane, B., Mahatoo, W., Heron, W., \& Scott, T. Changes in perceptual functioning after isolation. Canad. J. Psychol., 1959, $13,210-219$.

Duke-Elder, S. W. Textbook of ophthalmology. St. Louis: C. V. Mosby Company, 1949.

Friel, C. M., \& Derogatis, L. The effect of nonpatterned sensory deprivation on visual recognition thresholds. Psychon. Sci., $1965,3,163-164$.

Heron, W. The pathology of boredom. Scient. American, 1957, 196, 52.

Heron, W., Bexton, W. H., \& Hebb, D. O. Cognitive effects of decreased variation in the sensory environment. Amer. Psychologist, $1953,8,366$.

Lindsley, D. B. Common factors in sensory deprivation, sensory distortion, and sensory overload. In P. Solomon, P. E. Kubsansky, P. H. Leiderman, J. H. Mendelson, R. Trumbull, \& D. Wexler (Eds.), Sensory deprivation. Cambridge, Mass.: Harvard University Press, 1961.

Manas, L. Visual analysis. Chicago: The Professional Press, Inc. 1967.

Manas, L. A visual training method, personal communication, 1967.

Riesen, A. H. Excessive arousal effects of stimulation after early sensoty deptivation. In P. Solomon, P. E. Kubsansky, P. H. Leiderman, J. H. Mendelson, R. Trumbull, \& D. Wexler (Eds.), Sensory deprivation. Cambridge, Mass.: Harvard University Press. 1961.

Rosenbaum, G., Dobie, S., \& Cohen, B. D. Visual recognition threshold following sensory deprivation. Amer. J. Psychol., $1959,72,429$.

Schultz, D. P. Sensory restriction. New York: Academic Press, 1965.

Vemon, J. A., \& Hoffman, J. Effect of sensory deprivation upon rote learning in human beings. Science, 1956, 123, 1074.

Zubek, J. P., Flye, J., \& Altanas, M. Cutaneous sensitivity after prolonged visual deprivation. Science, 1964, 144, 1591-1593. 